\title{
A TRANSEXUALIDADE NA LITERATURA CIENTÍFICA DAS CIÊNCIAS DA SAÚDE
}

\author{
TRANSEXUALIDAD EN LA LITERATURA CIENTÍFICA \\ DE LAS CIENCIAS DE LA SALUD
}

\author{
Débora Gomes Salles * \\ Jéssica dos Santos Gonçalves ** \\ Luciana Danielli de Araujo ***
}

\begin{abstract}
RESUMO
Introdução: $O$ trabalho discute a visibilidade dos estudos científicos sobre transexualidade no campo da Saúde. Objetivos: O estudo questiona de que forma a transexualidade é abordada no campo na atualidade, tendo como margem temporal o período 2014-2016. Metodologia: A análise de domínio, proposta por Birger Hjørland e Hanne Albrechtsen, foi adotada, como abordagem teórico-metodológica, para o reconhecimento do grupo social transgênero como uma comunidade discursiva. A coleta de dados foi realizada na base LILACS, gerenciada pelo Centro LatinoAmericano de Informação em Ciências da Saúde (BIREME), a partir dos dados descritivos (centrando-se no título dos artigos), tendo como limitador do levantamento o(s) termo(s) "transexual(is)". Resultados: Foram recuperados 22 (vinte e dois) documentos no período. A partir destes, foram identificados para análise os seguintes metadados, autor, título, método e população de estudo utilizados, descritor, ano de publicação, sendo consideradas para o estudo, como centrais, os elementos "método" e "temacidade" (retirada a partir dos descritores). Após a análise do corpus, constatouse que os métodos adotados para abordar o tema são: estudos de narrativa; revisões de análises quali e quantitativas, estudos observacionais, revisões teóricas; análises de conteúdo, estudos comparativos, análises de discurso, revisões sistemáticas, entre outras citadas ao longo deste estudo. As principais ocorrências temáticas identificadas a partir dos descritores foram: pessoas, readequação, gênero, identidade, hormônios e saúde. Conclusões: Dentro dos limites da extensão e horizontalidade dos dados, depreende-se dos resultados que as Ciências da Saúde na América Latina e Caribe ainda estudam a transexualidade com foco na patologização dos indivíduos, principalmente a partir das representações manifestadas pelas noções "readequação" e "hormônios".
\end{abstract}

* Doutoranda do PPGCI, IBICT-UFRJ CPRM - Serviço Geológico do Brasil. Email: debora.g.salles@gmail.com.

** Mestranda do PPGCI, IBICT-UFRJ. Email: jessgoncal@gmail.com.

*** Fundação Oswaldo Cruz - Instituto de Comunicação, Informação Científica e Tecnológica em Saúde. Mestranda do PPGCI, IBICT-UFRJ. Email: Idaniellippgci@gmail.com.

Inf. Inf., Londrina, v. 22, n. 2, p. 265 - 292, maio/ago., 2017. http:www.uel.br/revistas/informacao/ 
Débora Gomes Salles, Jéssica dos Santos Gonçalves, Luciana Danielli de Araújo A transexualidade na literatura científica das ciências da saúde

Palavras-chave: Ciências da Saúde. Análise de domínio. Gênero. Transexualidade. Produção científica.

\section{INTRODUÇÃO}

Nesse trabalho, investigamos a produção de conhecimento científico sobre a transexualidade, com o intuito de discutir a abordagem epistemológica desse fenômeno nas Ciências da Saúde. Para isso, foi adotada a análise de domínio, proposta por Birger Hjørland e Hanne Albrechtsen (1995), como aporte metodológico no cenário da Organização do Conhecimento. A análise de domínio se propõe a estudar as comunidades de conhecimento como comunidades de discurso ou pensamento. Nesse cenário, busca identificar os mecanismos subjacentes ao comportamento informacional a partir das funções da informação e da comunicação dentro de um campo específico (HJØRLAND; ALBRECHTSEN, 1995).

A possibilidade de abordar o campo da Organização do Conhecimento a partir desse método se dá pelas características do objeto de estudo. Guimarães (2014) demonstra que o conhecimento registrado torna-se existente a partir de certo consenso social, evidenciado como objeto diante daquilo que podemos processar e sistematizar. Diante do tratamento (classificação, indexação, catalogação e arranjo) dado ao conhecimento registrado, entendese que a organização e disseminação de documentos visa fornecer o acesso, com objetivo de promover a recuperação da informação registrada.

Guimarães (2014) destaca uma característica distinta quanto à avaliação da ciência no que tange a construção do conhecimento, onde a forma em que é produzido orienta a prática, sua estrutura e registro, além de socializar um domínio científico. A análise de domínio permite identificar, classificar conceitos e suas relações de maneira que possa focalizar sua disposição através de facetas e categorias de uma tabela/lista. Para Campos e Gomes (2014), a modelagem de um domínio é elementar para a definição da unidade de representação, que sustentará a estrutura de classes deste domínio. Isto significa que o universo representado será aplicado ao domínio.

Inf. Inf., Londrina, v. 22, n. 2, p. 265 - 292, maio/ago., 2017. http:www.uel.br/revistas/informacao/ 
Neste sentido, em um determinado contexto, o caráter discursivo e/ou epistêmico tende a demarcar esquemas classificatórios do próprio domínio. Com isso, o objetivo deste estudo é realizar uma análise epistemológica, relacionada à elaboração de modelos conceituais, do domínio da transexualidade a partir da produção científica na área da Saúde. Isto é, pretendemos identificar os estudos existentes sobre o tema nas Ciências da Saúde e descrever as tendências de pesquisa da área. Definimos como corpus de análise os estudos científicos disponíveis na base LILACS (Literatura LatinoAmericana e do Caribe em Ciências da Saúde), um produto cooperativo coordenado pela BIREME/OPAS/OMS.

A estrutura do estudo foi definida respeitando as relações entre objetivo e abordagem metodológica. Dessa forma, realizamos uma breve revisão de literatura sobre informação e ciência da informação, organização do conhecimento, gênero e estudos de gênero, além de abordarmos a questão dos descritores relacionados a esses conceitos. Em seguida, descrevemos 0 método, caracterizando a abordagem da análise de domínio, o campo de pesquisa e a coleta de dados na base LILACS. Realizamos ainda, uma análise qualitativa sobre uma parte desses registros, indicando os principais pontos sobre as publicações coletadas. Finalmente, articulamos esses resultados com as questões temáticas levantadas pelo referencial teórico e apresentamos algumas tendências dos estudos nesse domínio, bem como possíveis implicações.

\section{REFERENCIAL TEÓRICO}

\section{a. Informação e Ciência da Informação}

A Ciência da Informação $(\mathrm{Cl})$ é uma área do conhecimento consideravelmente recente. Surgiu no século $X X$, a partir da preocupação com o aumento na quantidade de informações científicas que estavam sendo produzidas durante e após o período da Segunda Guerra Mundial. No cerne da Ciência da Informação está a informação, obviamente, bem como seu tratamento rápido e eficiente - através da descrição, indexação e classificação 
Débora Gomes Salles, Jéssica dos Santos Gonçalves, Luciana Danielli de Araújo A transexualidade na literatura científica das ciências da saúde

de documentos -, e sua recuperação a fim de embasar as pesquisas científicas.

Tendo se iniciado no começo dos anos 60 , prolongando-se até hoje, as questões acerca da natureza, manifestações e efeitos dos fenômenos básicos (a informação, o conhecimento e suas estruturas) e processos (comunicação e uso da informação) tornaram-se os principais problemas propostos pela pesquisa básica em Cl. (SARACEVIC, 1996, p. 46).

De acordo com Hjørland e Albrechtsen (1995) estudos como os citados por Saracevic (1996) são importantes, porém não deve ser deixado de lado o contexto em que estes estudos estão inseridos. Neste caso, o contexto engloba a sociedade ou comunidade de que trata o estudo, formada por pessoas que possuem cultura e realidade específicas, o que as supre de conhecimentos únicos. Esta comunidade possui um discurso com dogmas comuns e pode ser considerada uma comunidade de discurso.

Igualmente, Rafael Capurro (1992) apontou a necessidade de contextualização da informação na $\mathrm{Cl}$, com foco na cultura e história do contexto no qual se insere além de somente nos processos, métodos e interpretações utilizados para lidar com a informação, pois uma informação só faz sentido no contexto e propósito para o qual ela foi "criada". Portanto, as dimensões culturais, estéticas, éticas e políticas do sujeito a quem se pretende informar, o cidadão, o usuário, devem ser levadas em conta.

\section{b. Organização do conhecimento e domínio}

Há teóricos que pregam que a organização do conhecimento é uma das facetas da Ciência da Informação (HJØRLAND, 2008), e outros que a teorizam como uma nova área do conhecimento ou ciência, dissociada da $\mathrm{Cl}$ (DAHLBERG, 2006). Para o primeiro grupo, a organização do conhecimento não deve deixar de lado seu cunho social, o contexto e a comunidade de discurso para os quais as informações geradas serão organizadas. Para o segundo grupo, o foco da organização do conhecimento deve ser o aperfeiçoamento dos sistemas e métodos segundo os quais essas informações serão organizadas. No âmbito deste trabalho, apoiamos a visão do grupo que prega a primeira teoria, na qual organização do conhecimento e sociedade são 
indissociáveis, pois sem ela perde sua finalidade: organizar informações visando facilitar o acesso.

Hjørland e Albrechtsen (1995) propõem uma nova abordagem à organização do conhecimento e à Ciência da Informação. Eles afirmam que o estudo do conhecimento esteve por muito tempo direcionado aos processos cognitivos isolados do contexto sócio-histórico (em constante desenvolvimento) que gerou estes processos. Da mesma forma, os autores defendem a abordagem da análise de domínio como substitutiva à utilização dos processos cognitivos mentais - que veem o conhecimento como estados mentais individuais, i.e. a necessidade de informação por parte de um indivíduo esteja ele onde for será a mesma se seus objetivos forem iguais.

A abordagem da análise de domínio reconhece a existência de interações entre os indivíduos e a sociedade a qual fazem parte. Por isso, prega que "os indivíduos devem ser vistos como membros de grupos de trabalho, disciplinas, comunidades de pensamento ou de discurso, etc." e generalizações estão fora de questão (HJØRLAND; ALBRECHTSEN, 1995). Portanto, optamos por adotar a transexualidade como domínio, enquanto comunidade de pensamento e de discurso, com sua história e seus pontos de vista em comum.

\section{c. Estudos de gênero e o "fenômeno transexual"}

A palavra gênero tem significados diferenciados conforme varia 0 idioma. Em inglês, existe uma palavra para gênero (gender) e outra para sexo (sex). Em alemão, sexo e gênero são expressas pela palavra geschlecht que, além destes significados, também é traduzida como raça e família. Em inglês, alemão, francês (genre) e espanhol (género), a palavra gênero possui conotações literárias e gramaticais. Nas duas primeiras línguas, a palavra gênero refere-se também à sexualidade, diferença sexual, geração, engendramento, e outros termos correlatos, enquanto que nas duas últimas línguas esta ligação não é clara (HARAWAY, 2004).

A partir de meados da década de 1970, a temática Gênero começou a ser abordada na produção de estudiosos de disciplinas diversas. Os estudos eram predominantemente de cunho feminista, tendo como pano de fundo a luta 
das mulheres por direitos iguais aos conquistados pelos homens. Nestes estudos também eram questionados os papéis da mulher como dona de casa, mãe, submissa, sem pretensões profissionais diferentes do "cargo" de esposa (MATOS, 1998).

Estes estudos foram importantes para o avanço das discussões sobre Gênero, porém o enfoque excessivo na dicotomia homem e mulher, nos sexos, fez com que críticas e tensões começassem a surgir. Estas críticas eram provenientes de indivíduos que se sentiam excluídos, marginalizados, por essa dicotomia (MATOS, 1998; HARAWAY, 2004).

Nas décadas seguintes, os estudos feministas começaram a tratar a violência contra a mulher, as diferenças raciais e de classe (mulheres brancas e negras, livres e escravas, pobres e ricas), diferenças nos direitos adquiridos de acordo com a raça, etc. Estes estudos evidenciavam uma abertura no escopo do Gênero, que iniciava seu percurso rumo à inclusão das minorias.

Haraway (2004, p. 243) insiste na diferença da diferença para abordarmos o Gênero, onde não pode existir um sujeito coerente, constantemente imutável, na medida em que a personalidade individual é construída com o amadurecimento do ser humano e onde "[...] cada condição de opressão requer análise específica que recusa a separação, mas insiste na não identidade de raça, sexo e classe."

Partindo para a esfera transexual ou transgênero, os primeiros estudos que registraram e defenderam o "fenômeno transexual" datam da década de 1950. As autoras Bento e Pelúcio (2012a, 2012b), Bento (2011), Louro (2001) e Pino (2007) são as referências escolhidas para problematizar o universo transexual e os estudos sobre teoria queer no Brasil, que servirão de suporte na análise do domínio transexual.

Não há um padrão de identidade transexual. O que define a vivência transexual é a existência e o pertencimento social em um gênero distinto daquele que the foi imposto através do nascimento. Essa questão exclui os travestis e transexuais de todos os campos sociais existentes, o que gera desconfortos, podendo acarretar em sérios problemas psicológicos aos indivíduos transexuais. Portanto, há a busca pela permissão de mudança de 
nome e sexo nas instituições sociais e de direito, dentro de seus limites. Além disso, as demarcações exclusivas às demandas colocadas pela transexualidade e travestilidade fogem daquilo que a sociedade considera normal, ou seja, do que evocamos como dado natural, o corpo-sexuado que é resultante da normatização de gênero.

Para Bento e Pelúcio (2012a) sofremos influências culturais desde nosso nascimento, pois o campo discursivo da sociedade em que iremos habitar já vêm sendo construído desde muito antes. Vale lembrar que vivemos, desde longa data, a produção de um projeto de gênero para a humanidade com foco no binarismo homem e mulher.

Contra o binarismo e as normas heterosexuais surge a teoria queer que, para Judith Butler (2006 apud PINO, 2007) desenvolveu-se com base na teoria da performance de gênero, utilizada para justificar a mimetização do sexo oposto por parte de drag queens, travestis e, algumas vezes, transexuais.

Outro impulsionador para o surgimento da teoria queer foi 0 questionamento das estratégias de divulgação política da comunidade homossexual, ocorrida a partir da década de 1970. Esta divulgação apresentava o indivíduo homossexual como de cor branca, do sexo masculino, monogâmico e integrante da classe média alta, o que gerou um sentimento de exclusão em negros, latinos, jovens, lésbicas, bissexuais, sadomasoquistas e transexuais, também integrantes desta comunidade (LOURO, 2001).

De acordo com Pino (2007, p. 163) na teoria queer

[...] o importante é lutar contra as formas de legislação universal das identidades e saber discernir que o aceitável para um grupo pode não ser para os outros, distinguindo, assim, os diferentes níveis que conferem habitabilidade aos indivíduos e pensando em estratégias que possam melhorar os conflitos com as normas de gênero. As críticas às normas devem situarse no contexto em que essas vidas são vividas e guiar-se pelas condições que maximizam as possibilidades de ter uma vida habitável. Tanto os transexuais quanto os intersex reivindicam vidas habitáveis, mas essas só existem na medida em que concordam com as categorias de reconhecimento. (PINO, 2007, p. 163, grifo nosso). 
Portanto, a teoria queer é compreendida e representada como aquela que desorganiza os instrumentos normatizadores da heterossexualidade, que visa descontruir para pluralizar as identidades. A construção da teoria queer está fundamentada na teoria da performance de gênero para rejeitar qualquer tipo de "fundacionismo biológico", opor-se ao heterosexismo imposto nos estudos feministas e por entender que os queer vivem e confrontam as normas de gênero. Atualmente, o termo queer ganhou significado político e teórico nas pesquisas e discussões do conceito, apropriado por vários segmentos, inclusive o de transexuais, que defendem e lutam por uma sociedade diversa e plural.

O estado adequado de uma pessoa [...] é o de ter o comando do ser, de ter e manter uma identidade centrada, como se fosse uma posse. Esta posse pode ser feita de variados materiais brutos ao longo do tempo, isto é, pode ser uma produção cultural, ou pode-se nascer com ela. A identidade de gênero é uma posse deste tipo. Não ter a propriedade do eu é não ser sujeito e, portanto, não ter capacidade de atuação. (HARAWAY, 2004, p. 220).

Inserindo o domínio transexual na área das Ciências da Saúde, Bento e Pelúcio (2012b) problematizam a relação transexualidade e travestilidade, considerado através de organismos internacionais, instituições e associações que definem e classificam ambas como característica diagnóstica no campo da Saúde. Neste aspecto, são classificadas como "Transtornos de Identidade de Gênero". As listas classificatórias discutidas pelas autoras são: o Manual Diagnóstico e Estatístico dos transtornos mentais (DSM-IV), de responsabilidade da Associação de Psiquiatria Norte-Americana (APA), o Código Internacional de Doenças (CID-10), publicado pela Organização Mundial da Saúde (OMS), e a SOC, que defendem como alternativa para resolver os "transtornos" ou "disforias" através de cirurgias de transgenitalização (BENTO; PELÚCIO, 2012b).

Bento (2011) discute as limitações/ausências na abordagem do heteroterrorismo no ambiente escolar. Aborda a desumanização como ponto central da manutenção da heteronormatividade que funciona como instituição 
guardiã das normas de gênero, incapaz de lidar com a diversidade. Utilizando as listas classificatórias construídas pelo modelo biomédico e citadas anteriormente, a autora corrobora as limitações no enfrentamento das diferenças no cotidiano das escolas.

No século XX, sobretudo a partir do final da década de 1980, as políticas públicas brasileiras de apoio aos indivíduos transexuais evoluíram expressivamente, principalmente pelo esforço no combate à epidemia da Aids por parte do Ministério da Saúde e movimentos sociais vinculados à defesa dos direitos de grupos homossexuais (BRASIL, 2013). Também é dessa década a Constituição Federal de 1988, que em seu artigo 196 diz que
A saúde é direito de todos e dever do Estado, garantido mediante políticas sociais e econômicas que visem à redução do risco de doença e de outros agravos e ao acesso universal e igualitário às ações e serviços para sua promoção, proteção e recuperação. (BRASIL, 1988, grifo nosso).

Com base no exposto acima, todo(a) brasileiro(a), incluídos os indivíduos transexuais, tem seu direito à saúde garantido pela Constituição. Reforçando o direito à saúde, atenção e cuidado dos indivíduos transexuais, em 1997 o Conselho Federal de Medicina aprovou a Resolução 1.482, possibilitando que hospitais públicos universitários realizassem cirurgias de redefinição de sexo (transgenitalização) em transexuais, à título experimental. Em 2002 essa resolução foi atualizada pela Resolução 1.652, retirando o caráter experimental da cirurgia de neocolpovulvopastia. A atualização possibilitou "o atendimento das transexuais femininas em qualquer instituição de saúde, pública ou privada [...]" do país (ARÁN et al., [2008?]).

O direito à realização da cirurgia de transgenitalização e tratamento hormonal através do Sistema Único de Saúde (SUS), concedido pelo Supremo Tribunal Federal (STF) brasileiro em 2001, foi de extrema importância para a população transexual. Contudo, é necessária a manutenção da individualidade em cada caso (ARÁN et al., [2008?]). Só porque um indivíduo é homem e se considera mulher, ou vice-versa, não quer dizer que ele queira de fato sê-lo. Portanto, a exigência de cirurgia de transgenitalização como contrapartida para 
o processo de alteração jurídica da identidade limita e obriga o indivíduo transexual a submeter-se à cirurgia mesmo contra a sua vontade, como meio de conquistar o direito à vida digna.

O direito à saúde, nos casos de transexuais, passa pelo direito à autonomia na tomada de decisão sobre os procedimentos necessários para uma melhor qualidade de vida, pelo direito ao livre desenvolvimento da personalidade, à não discriminação, bem como à liberdade e à singularidade (ARÁN; LIONÇO, 2008, apud ARÁN et al., [2008?], p. [5]).

Ainda quanto às políticas públicas e o acesso à saúde, os indivíduos transexuais tiveram um avanço expressivo em seus direitos a partir da Política Nacional de Saúde Integral de Lésbicas, Gays, Bissexuais, Travestis e Transexuais, que consiste em "documento norteador e legitimador das suas necessidades e especificidades, em conformidade aos postulados de equidade previstos na Constituição Federal e na Carta aos Usuários do Sistema Único de Saúde" (BRASIL, 2013, p. 6).

Diante de tais circunstâncias, iniciativas como a campanha internacional pela despatologização das identidades sexuais e a análise dos manuais médicos que classificam o gênero como uma característica diagnóstica, reúnem todo o esforço de reconhecimento da luta pelo fim do diagnóstico de gênero (BENTO; PELÚCIO, 2012b).

Percebemos que a realização de estudos sobre o domínio transexual muito tem a contribuir nas mais variadas esferas do conhecimento, além de dar voz a indivíduos que há muito vem sendo marginalizados socialmente.

\section{d. MÉTODO}

Birger Hjørland (2002) aponta que a análise de domínio oferece investigações práticas e empíricas relevantes para o campo de estudo da Ciência da Informação. O autor aponta 11 abordagens que podem ser adotadas para entender os domínios analisados. Dentre essas abordagens, escolhemos os estudos epistemológicos e críticos, indicadores de fundamentos e paradigmas do campo estudado, a partir de avaliações críticas das 
reinvindicações de conhecimento realizadas pelo campo da transexualidade em periódicos das Ciências da Saúde (HJØRLAND, 2002).

A análise proposta por Hjørland (2002) procura distinguir fundamentos, escolas de pensamento, metodologias e técnicas, formando uma hierarquia de quatro camadas do geral para o específico. O interessante nessa proposta é a perspectiva crítica que busca explicar o comportamento da informação no contexto de determinado domínio, fornecendo diretrizes para entendermos suas bases e estruturas teórico-metodológicas, e como a informação é produzida, organizada, indexada, avaliada, consumida, disseminada e reproduzida neste contexto.

Adotamos aqui uma abordagem não-obstrutiva seguida de análises qualitativas e quantitativas. Uma vez que o objetivo geral deste estudo é discutir a produção de discurso sobre a transexualidade nas Ciências da Saúde, realizamos uma busca bibliográfica sobre o fenômeno na base LILACS. Analisamos, então, os dados descritivos desses estudos, assim como suas perspectivas teórico-metodológicas. As etapas percorridas estão detalhadas no decorrer dos próximos pontos.

\section{e. A base LILACS}

O Centro Latino-Americano e do Caribe de Informação em Ciências da Saúde é mais conhecido pela sigla BIREME, baseada na sua denominação original Biblioteca Regional de Medicina. É um organismo internacional que faz parte da Organização Pan-Americana da Saúde e Organização Mundial da Saúde (OPAS/OMS) e funciona como um centro especializado. Ele surgiu dos esforços entre países, organismos internacionais, órgãos ministeriais, universidades e escolas médicas, na criação da Biblioteca Regional de Medicina, iniciativa inspirada no modelo americano de gestão de informação científica da U.S. National Library of Medicine (NLM) (PIRES-ALVES, 2011).

O desenvolvimento de sistemas de informação e o avanço tecnológico ocorridos na década de 80 proporcionaram ao campo da Saúde, por meio da BIREME/OPAS, o desenvolvimento de uma base de dados (denominada LILACS, de Literatura Latino-americana e do Caribe de Informação em 
Ciências da Saúde). A base é alimentada pela descrição e indexação de registros para prover a disseminação e o acesso à informação sobre a produção científica em Ciências da Saúde produzida na América Latina e no Caribe. Essa base é operada em rede de forma cooperativa com o intuito de realizar o controle bibliográfico da região coberta.

A LILACS é o mais importante e abrangente índice da literatura científica e técnica da América Latina e Caribe, com ênfase na área da Saúde Pública. Sua cobertura temática abrange as Ciências da Saúde em geral, incluindo áreas que tenham relação com a saúde humana e animal: Medicina, Saúde Pública, Odontologia, Enfermagem, Veterinária, Farmácia e Química, Biologia, Nutrição, Psicologia, Meio Ambiente e outras. A base está presente em 27 países do território latino-americano e do Caribe, com 906 títulos de periódicos indexados e mais de 350 mil textos completos entre teses, livros, artigos, relatórios de pesquisa e publicações governamentais.

\section{f. O domínio de gênero e a transexualidade}

A partir de uma lista desenvolvida com termos do domínio gênero ${ }^{1}$, localizamos na base LILACS a sua frequência nos documentos indexados. Pretendemos aqui testar termos que dialogassem com o fenômeno - e domínio - da transexualidade. A partir da busca por essas palavras, mapeamos os clusters de assunto principal dos documentos e revistas, ambos tipos de documentos disponíveis na base LILACS. Estes clusters são resultado da atividade de indexação nos processos de cadastro dos documentos na base de dados. Essa busca foi realizada a partir da opção "palavras do título". O gráfico abaixo mostra a revocação de cada termo na base.

\footnotetext{
1 Se faz necessário frisar que a lista não é exaustiva e não aborda todos os termos que podem estar relacionados ao domínio citado.
}

Inf. Inf., Londrina, v. 22, n. 2, p. 265 - 292, maio/ago., 2017. http:www.uel.br/revistas/informacao/ 
Débora Gomes Salles, Jéssica dos Santos Gonçalves, Luciana Danielli de Araújo A transexualidade na literatura científica das ciências da saúde

Gráfico 1 - Revocação de termos do domínio gênero pesquisados na base LILACS

2517

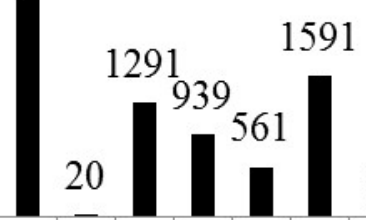

$\begin{array}{lllllllllllllllllll}5 & 33 & 9 & 7 & 90 & 1 & 9 & 0 & 98 & 12 & 12 & 0 & 1 & 0 & 19 & 34 & 10 & 8 & 2\end{array}$

Fonte: As autoras

O termo gênero é o mais frequente - e também mais geral - com 2.517 ocorrências. Os termos mulher, sexo e sexualidade também tiveram forte presença nos registros. Alguns termos não foram encontrados: intersexo; crossdressing; drag king. Isso pode ser explicado pelo fato de serem conceitos mais recentes do domínio gênero. Os termos homoafetividade, machismo, teoria queer e drag queen apresentam baixa presença na base, provavelmente por estarem relacionados às questões mais caras às Ciências Sociais do que às Ciências da Saúde.

A respeito do assunto principal dos estudos, a questão da identidade de gênero é o mais comum para vários dos termos pesquisados (gênero, estudos de gênero, identidade sexual, identidade de gênero, igualdade de gênero). Transexualismo e psicologia social também figuram como assuntos recorrentes. O assunto sexualidade é abordado a partir de diferentes perspectivas, sendo discutido do ponto de vista da diferença sexual, da noção de queer e da própria sexualidade.

Sobre os assuntos das revistas, a Psicologia é o assunto mais recorrente, seguida de Ciências do Comportamento. É interessante ressaltar que epidemiologia aparece como o assunto principal mais recorrente dos termos heterossexualidade e igualdade de gênero, o que pode ter relação com os problemas que envolvem à questão de doenças como HIVIAIDS e/ou outras doenças contagiosas. Outro ponto interessante é a relação entre homem e cardiologia e mulher e enfermagem. Esse ponto demonstra uma tendência de interesses de pesquisa ou ainda de atuação profissional. Finalmente, 
percebemos que para o termo intersexo o assunto mais frequente é a Endocrinologia, apontando para a discussão da questão hormonal que permeia a identificação e expressão de gênero.

Com essa busca preliminar, percebemos que os termos sexo, sexualidade, homem, mulher, machismo, feminismo, diferença sexual, heterossexualidade, homossexualidade, queer e teoria queer tratam de assuntos não pertinentes ao escopo da revisão. Notamos ainda que os termos travesti e transgênero remetiam aos mesmos registros revocados pelo termo transexualidade. Com isso, definimos que nossa análise seria feita apenas a partir do termo transexuais.

\section{g. O poder classificatório dos descritores}

Diante das relações hegemônicas sobre os termos definidos nas listas classificatórias normatizadoras dos campos Biomédico e da Saúde, destacamos como exemplo da influência sobre o pensamento do domínio gênero o termo "transexualidade". Isto é, buscamos discutir de forma mais aprofundada os estudos sobre a noção de transexualidade e seus desdobramentos. Esta forma de definir e classificar conceitos reflete também no campo da organização do conhecimento.

Numa perspectiva aplicada, é possível analisar os instrumentos de indexação, como os vocabulários controlados, tesauros e glossários. A análise de sua organização temática, por meio das categorias pré-estabelecidas pelas áreas do conhecimento dominantes é um caminho para discutir as relações de poder entre áreas de pesquisa. Destacamos o exemplo de um vocabulário controlado do campo da Saúde: o DeCS (Descritores em Ciências da Saúde).

O DeCS é um vocabulário controlado, trilíngue, criado pela BIREME em 1982. Este instrumento faz parte da metodologia da base LILACS e da Biblioteca Virtual em Saúde (BVS), um sistema de informação desenvolvido a partir da descrição e indexação de registros bibliográficos por meio da catalogação cooperativa.

O DeCS é uma tradução adaptada do Medical Subject Headings (MeSH) da NLM. Além de contar com os termos médicos originais do MeSH, no DeCS 
Débora Gomes Salles, Jéssica dos Santos Gonçalves, Luciana Danielli de Araújo A transexualidade na literatura científica das ciências da saúde

foram desenvolvidas, sob a liderança do Brasil, as áreas (categorias) específicas de Saúde Pública, Homeopatia, Ciência e Saúde e Vigilância Sanitária.

O termo transexualismo e seu sinônimo transexualidade remetem a uma definição no vocabulário como um estado patológico, uma "disforia grave". Essa concepção é fortemente influenciada pelo estabelecido no CID-10 da OMS e na DSM-IV da American Psychological Association, organismos e associações norte-americanas. O entendimento médico quanto aos indivíduos transexuais repercute no entendimento social dessa condição. Isto é, diante da autoridade médica e de sua definição, a sociedade concebe a transexualidade como uma doença.

A visão acima afeta as possibilidades ofertadas à população transexual: desde a realização de cirurgia de readequação sexual até a utilização do nome social em instâncias oficiais. Tal compreensão influencia ainda no preconceito que incide sobre a população cisgênero, sua identificação e expressão de gênero não normativa.

Diante de tais circunstâncias, é crucial o questionamento dos manuais médicos que classificam o gênero como uma característica diagnóstica. Vale ressaltar a campanha mundial do Dia internacional pela despatologização das identidades trans que acontece no mês de outubro e a campanha do Dia Mundial de Luta contra o HIVIAIDS, no dia $1^{\circ}$ de dezembro. Estas são iniciativas importantes, pois a mobilização é organizada pelos movimentos associativos, instituições de defesa e entidades que lutam pelos direitos e reconhecimento da diversidade, onde são debatidas as experiências culturais, políticas e subjetivas de gênero e sexualidade ${ }^{2}$.

2 (Conselho Federal de Psicologia. Disponível em: http://site.cfp.org.br/dia-internacional-peladespatologizacao-das-identidades-trans/). Para maiores informações: https://pt.wikipedia.org/wiki/Transtorno de identidade de g\%C3\%AAnero.

Inf. Inf., Londrina, v. 22, n. 2, p. 265 - 292, maio/ago., 2017. http:www.uel.br/revistas/informacao/ 
Débora Gomes Salles, Jéssica dos Santos Gonçalves, Luciana Danielli de Araújo A transexualidade na literatura científica das ciências da saúde

\section{h. Protocolo de pesquisa}

Para estudar a constituição do domínio da transexualidade, foi realizado um levantamento de trabalhos existentes na base LILACS a partir da busca pelo termo "transex\$" - que inclui as variantes transexual, transexuais, transexualismo e transexualidade. Buscando por "palavras do título" dos documentos, foram encontrados 98 resultados. A partir do cluster/filtro ano, usando o período 2014-2016, a amostra foi reduzida para 23 resultados, dentre os quais um estava duplicado, totalizando então 22 documentos para análise: 20 artigos, 1 (uma) resenha e 1 (uma) dissertação.

Foi feita, em seguida, uma análise dos clusters da base de dados LILACS a partir dos metadados coletados de cada resultado, tabulados usando os seguintes filtros: Autor/título; Método/População de estudo; Palavras-chave; Revista; Assunto da Revista; Ano do artigo; País; e Contribuição do documento.

\section{i. RESULTADOS}

Partindo para a análise dos resultados encontrados, verificou-se nos 22 registros analisados um total de 51 autores identificados pelo cluster/filtro de autoria/título dos documentos. A média de autores por artigo foi de 2,3.

Na tabela 1 podemos observar o cluster ano de publicação (20142016), onde o ano de 2015 foi o de maior produção dentro do levantamento.

Tabela 1 - Quantidade de publicações x cluster/filtro "Ano de publicação"

\begin{tabular}{llll} 
Ano & Artigos & Dissertações & Total \\
\hline 2014 & 8 & 1 & 9 \\
2015 & 9 & 9 \\
2016 & 4 & 4
\end{tabular}


Débora Gomes Salles, Jéssica dos Santos Gonçalves, Luciana Danielli de Araújo A transexualidade na literatura científica das ciências da saúde

$\begin{array}{lll}\text { Total } & 21 & 1\end{array}$

Fonte: As autoras.

Em relação ao cluster países, no período estudado, o Brasil possui 16 artigos e 1 dissertação publicados, enquanto Argentina, Colômbia, Chile, Perú e Venezuela possuem somente 1 artigo cada. Observamos, portanto, que o Brasil foi o país que obteve maiores resultados, como mostra o gráfico 3 .

Gráfico 2 - Cluster/filtro "País de Publicação" na base LILACS

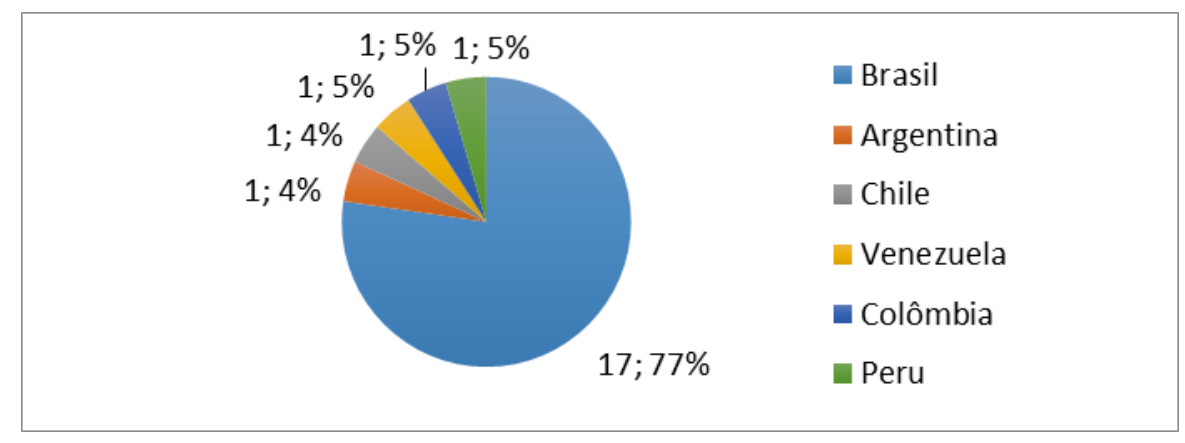

Fonte: As autoras.

O cluster/filtro de palavras-chave demonstra os termos utilizados para representar tematicamente a transexualidade nos registros encontrados na base de dados. Reunimos as palavras-chave dos autores dos documentos com descritores do DeCS, utilizados na indexação realizada na base LILACS. As palavras-chave mais frequentes foram: pessoas transgênero, identidade de gênero, transexualismo, transexualidade, cirurgia de adequação sexual e serviços de saúde.

Os assuntos indexados pelas palavras-chave estão mais voltados para questões relacionadas à busca da população LGBTT aos serviços de saúde de uma maneira geral, para diagnóstico e tratamento no que se refere às cirurgias de readequação sexual, à busca da identidade de gênero, questões referentes à transexualidade e transexualismo, ao uso terapêutico de hormônios, ao direito à saúde, à legislação sobre os pedidos de mudança de sexo e nome, às questões da violência, entre outros.

Inf. Inf., Londrina, v. 22, n. 2, p. 265 - 292, maio/ago., 2017. http:www.uel.br/revistas/informacao/ 
Referente ao método/população de estudo, criou-se este filtro a partir das leituras dos resumos dos registros do corpus de análise, identificando seus tipos de estudos ou metodologias utilizadas nas pesquisas realizadas. As metodologias reveladas foram categorizadas primeiramente pelo tipo de dado produzido e analisado: pesquisas empíricas (dados primários) e teóricas (dados secundários).

Em seguida, as pesquisas empíricas foram dividas a partir do(s) tipo(s) de análise(s) realizada(s): natureza quantitativa, qualitativa, e quali e quanti. É importante ressaltar o fato de que um único estudo pode utilizar mais de uma metodologia. O gráfico 3 indica a distribuição dos resultados segundo essas categorias.

Gráfico 3 - Cluster/filtro "Metodologia" na base LILACS

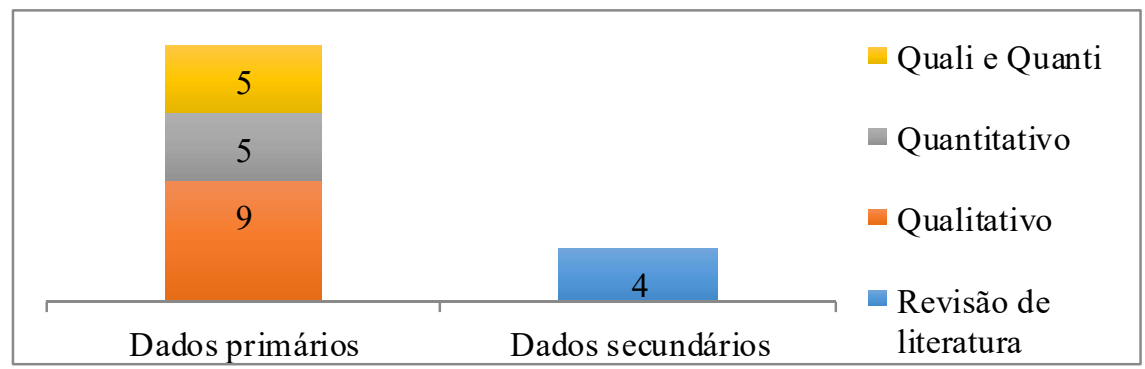

Fonte: As autoras.

Verificou-se um número expressivo de metodologias utilizadas para desenvolvimento dos estudos sobre transexualidade como: Estudos de Narrativas; Estudos Epidemiológicos - Prevalência; Estudos Transversais Descritivos; Análises Quantitativas; Resenha; Estudos Observacionais; Revisões Teóricas; Análise de Conteúdo; Estudos Comparativos; Estudos Qualitativos Questionários; Análise do Discurso; Revisões Sistemáticas; Estudo das Representações Sociais; Estudos Epistemológicos. Os estudos analisados tiveram como população: indivíduos/ comunidade LGBTT, pessoas transgênero, travestis, transexuais e homossexuais.

O cluster/filtro "Assunto da Revista" identifica a área de escopo das revistas em que estão publicados os registros encontrados na base LILACS. Com relação à área de escopo das revistas, realizamos a divisão em quatro 
grandes temas (gráfico 4), tendo em mente as suas subáreas temáticas, pois identificamos que alguns periódicos possuem mais de uma área em seu escopo.

Os assuntos principais das revistas foram arranjados nas áreas Medicina, Enfermagem, Psicologia e Saúde Pública. É importante ressaltar que os periódicos estão classificados em mais de uma área, proporcionando uma diversidade de categorias nas publicações. Também por essa razão, o resultado de periódicos por áreas tem somatório (29) maior que a quantidade de artigos encontrados (21).

Gráfico 4 - Cluster/filtro "Assunto da Revista" na base LILACS

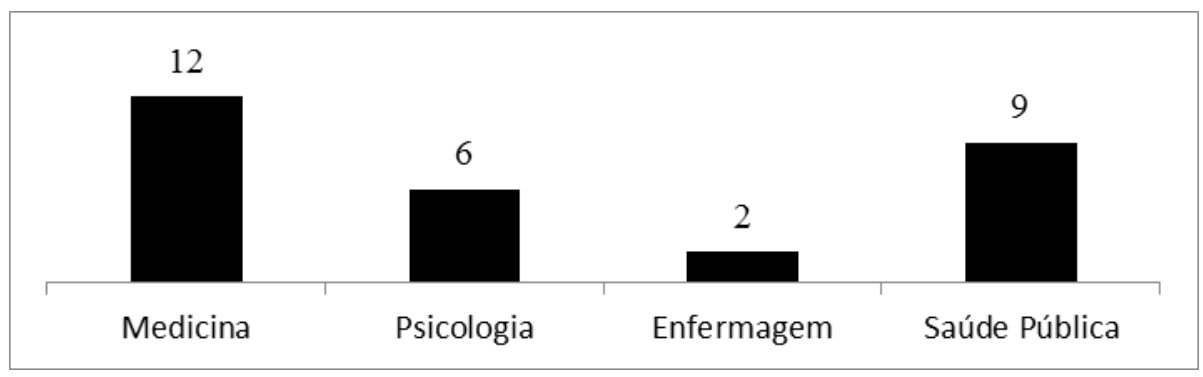

Fonte: As autoras.

Por exemplo, a Revista Médica do Chile, classificada como um periódico da área médica, teve um artigo sobre o reconhecimento legal dos pedidos de mudança de nome e de sexo pelas pessoas transgênero no Chile utilizado neste estudo. Outro exemplo interessante é o do periódico Revista Sexualidad, Salud, y Sociedad que se encontra classificada em 3 das 4 grandes áreas de escopo (Medicina, Saúde Pública e Psicologia), que traz na seleção um artigo que relata a questão do uso de hormônio em homens transexuais e a produção do cuidado em saúde.

A partir dos dados apresentados acima, verifica-se o interesse dos periódicos em divulgar os conhecimentos produzidos sobre transexualidade. A presença de periódicos como a Revista Gaúcha de Enfermagem, a Revista Médica do Chile, Revista Sexualidad, Salud, y Sociedad - Revista Latinoamericana, para citar algumas, nos esclarece o quanto é importante 
Débora Gomes Salles, Jéssica dos Santos Gonçalves, Luciana Danielli de Araújo

A transexualidade na literatura científica das ciências da saúde

discutir e relativizar o trabalho multidisciplinar no desenvolvimento da produção do conhecimento sobre a transexualidade em Saúde.

\section{ANÁLISE E DISCUSSÃO}

Diante dos dados apresentados no item anterior, se fez necessário buscar a ideia-chave dos registros recuperados a partir da interpretação de suas temáticas centrais, dialogando à luz das questões problematizadas pelos autores quanto à pesquisa no domínio transexualidade. Para realizarmos essa análise, definimos dimensões temáticas a partir do referencial teórico apresentado no item 3. $\mathrm{O}$ intuito foi esquematizar as abordagens temáticas e os caminhos de pesquisa por elas apontados. Nesse sentindo, as dimensões temáticas abordadas no âmbito dos estudos que tratam do domínio transexual são:

1. Dimensão biomédica - diz respeito ao diagnóstico, tratamento e acompanhamento dos indivíduos transexuais nos serviços de saúde. Compreende a cirurgia de transgenitalização, tratamentos hormonais, acompanhamento psicológico e demais procedimentos médicos aplicados à população transgênero.

2. Dimensão legal e da representação social dos indivíduos transexuais direito humano e social, diz respeito à legislação (leis, emendas, resoluções, políticas, etc.) e à representação social de indivíduos transexuais.

3. Dimensão do cuidado e acesso integral à saúde - compreende estudos que tratam da ampliação do acesso a ações e serviços de saúde de qualidade, com vistas à redução da desigualdade do grupo social transgênero na esfera da Saúde. Inclui programas de conscientização e prevenção de doenças.

4. Dimensão do preconceito, violência, discriminação e vulnerabilidade social - diz respeito a estudos que tratam dos efeitos da discriminação e da exclusão, visando o respeito sem preconceito, e sem discriminação e violência dos indivíduos transexuais junto à sociedade civil. A vulnerabilidade social dos transgêneros é agravada pelo fato de, muitas vezes, terem que sujeitar-se à prostituição como única saída empregatícia, aumentando os riscos de serem violentados e contraírem doenças sexualmente transmissíveis.

5. Dimensão da psicanálise e da teoria da construção social - corresponde à estudos acerca da aceitação e apoio psicológico recebidos pelos transgêneros junto à família e à sociedade, a auto aceitação, bem como dos problemas decorrentes da situação inversa. Também pode conter

Inf. Inf., Londrina, v. 22, n. 2, p. 265 - 292, maio/ago., 2017. http:www.uel.br/revistas/informacao/ 
Débora Gomes Salles, Jéssica dos Santos Gonçalves, Luciana Danielli de Araújo A transexualidade na literatura científica das ciências da saúde

estudos sobre o fortalecimento da representação transgênero nas instâncias políticas e de participação popular.

Naturalmente essas dimensões se inter-relacionam e os registros analisados abordam mais de uma delas. O esforço aqui realizado foi identificar o(s) assunto(s) central(is) de cada estudo para dialogar com as questões do domínio transexualidade. Com isso, é possível compararmos as iniciativas de indexação da base com os temas abordados efetivamente pelos estudos, como mostra a tabela 2.

Tabela 2 - Dados comparativos sobre as dimensões aplicadas sobre os estudos de transexualidade e a representatividade temática das Revistas LILACS

\begin{tabular}{|c|c|c|c|c|}
\hline \multirow[b]{2}{*}{ DIMENSÕES } & \multicolumn{4}{|c|}{ ASSUNTOS DA REVISTA } \\
\hline & Medicina & Enfermagem & Psicologia & Saúde pública \\
\hline $\begin{array}{l}\text { Discriminação e vulnerabilidade } \\
\text { social }\end{array}$ & & A4 & & A3, A7 \\
\hline $\begin{array}{l}\text { Cuidado e acesso integral à } \\
\text { saúde }\end{array}$ & & & & A15, A19 \\
\hline $\begin{array}{l}\text { Biomédico para diagnóstico e } \\
\text { tratamentos dos serviços } \\
\text { clínicos de saúde }\end{array}$ & $\begin{array}{c}\text { A1, A11, } \\
\text { A14, } \\
\text { A18, A20 }\end{array}$ & A12 & A1, A13 & A1, D21 \\
\hline Psicanálise e construção social & $\begin{array}{l}\text { R5, A6, } \\
\text { A10 }\end{array}$ & & A9, A10 & \\
\hline Direito e representação social & $\mathrm{A} 2, \mathrm{~A} 8$ & & $\mathrm{~A} 2, \mathrm{~A} 16$ & $\mathrm{~A} 2, \mathrm{~A} 17$ \\
\hline
\end{tabular}

A maioria dos estudos se concentra na dimensão biomédica, mas é interessante perceber que a questão legal e de representação social do individuo transexual também é largamente estudada. Outro ponto interessante que se pode notar é como as revistas do assunto Saúde Pública são capazes de incluir quase todas as dimensões temáticas do domínio transexualidade. Se as contrapormos com as revistas do assunto Enfermagem, por exemplo, vemos como este campo temático é mais reduzido que o anterior.

A dimensão do preconceito, violência, discriminação e vulnerabilidade é abordada não só pela Saúde Pública, mas também pelas revistas de Enfermagem, o que pode demonstrar uma interface do campo com o apoio 
social e não apenas com as questões biomédicas. A dimensão psicológica, apesar de incluir as discussões sociais, é abordada prioritariamente por publicações de Medicina. Podemos ainda problematizar a ausência de discussões sobre essa questão em revistas da dimensão Saúde Pública.

Vale ressaltar que tais assuntos e áreas de escopo das revistas nos remetem ao papel desenvolvido pelas políticas públicas de saúde. Elas são embasadas em aportes teóricos da pesquisa científica, do dever do Estado para com o direito à saúde provido por instituições governamentais e dos movimentos associativos através do controle social na Saúde. Enquanto alguns interpretam o acesso aos serviços públicos de saúde por parte dos cidadãos transexuais pura e simplesmente como um meio de alcançar o processo transexualizador, os cidadãos transgêneros e profissionais da Saúde conhecem sua real finalidade: garantia de acesso à saúde integral para a população LGBTT, de forma equânime.

Nos dados obtidos, podemos verificar que a transexualidade está avançando no processo de consolidação como domínio, ponto apontado por Bento e Pelúcio (2012) e Arán et al. ([2008?]), embora também tenham sido constatadas algumas limitações quanto à ampliação da produção de conhecimento multidisciplinar e intersetorial do trabalho em Saúde. Outro aspecto limitador corresponde à ausência de estudos que tratem da "filosofia queer", especificamente na América Latina, situação constatada por Pino (2007). Nos resultados desta pesquisa, encontramos apenas um documento que abordava esta questão.

Um fato interessante foi o encontro, em um dos registros, de uma dissertação que discute o domínio transexualidade no campo da Saúde. Ela corrobora a noção do "fenômeno transexual" como um domínio que enfrenta e discute as barreiras classificatórias. As listas categóricas nos impõem definições e conceitos para domínios que reforçam o arquétipo binário e o heteroterrorismo, apontado por Bento (2011). O tema da transexualidade se apresenta, naturalmente, como uma discussão sobre essas limitações.

Neste aspecto, os autores citados no referencial teórico apontam que existe uma aliança entre informação, educação, justiça, comportamento e 
saúde na busca por direitos e pela dignidade humana. Essa aliança apresenta desdobramentos aplicados no desenvolvimento de programas, políticas públicas, e ações para acesso aos serviços de saúde para obter e promover seu acesso equitativo.

Podemos fundamentar as dimensões aplicadas a partir da formulação das políticas de saúde que corroboram a defesa dos direitos da população LGBTT, cobrindo a melhoria e avanços no diagnóstico e tratamento das pessoas transgênero como, por exemplo, a ampliação do processo transexualizador; o direito à saúde como um direito humano e social; a produção do cuidado e acesso integral à saúde; a luta contra o preconceito, a violência e a discriminação, bem como a vulnerabilidade social de pessoas transgênero; e a busca da teoria da construção social, da psicanálise, junto à contribuição dos estudos sobre o domínio transexualidade e identidade de gênero no campo da Saúde.

A Política Nacional de Saúde Integral de Lésbicas, Gays, Bissexuais, Travestis e Transexuais do Ministério da Saúde apresenta desafios aos campos da Saúde, Educação e Direitos Humanos, e outras áreas de atuação da sociedade, pela sua capacidade intersetorial de mobilização, pois marca a conquista de aspectos legais e políticos no enfrentamento ao preconceito e a discriminação em relação à orientação sexual e a identidade de gênero no Brasil. A Política consiste em levantar esforços para construir um país diverso, justo e mais plural na luta pelo respeito e cidadania articulados à atuação do Sistema Único de Saúde (SUS), por intermédio de seus trabalhadores, no atendimento integral e equânime à população.

As políticas públicas promovidas para a população transexual são valorizadas pelos estudos, uma vez que o SUS realiza cirurgias de redesignação sexual, disponibiliza tratamento hormonal e promove iniciativas sociais de combate ao preconceito. Outro ponto mencionado pelos estudos é a política de HIVIAIDS no Brasil, fato exaltado na Política de saúde integral LGBT (BRASIL, 2008) e também por Arán et al. ([2008?]). A política de HIVIAIDS é vista como empreendimento crucial para a garantia de direitos, saúde, seguridade social e qualidade de vida à população transexual soropositiva. Tais 
Débora Gomes Salles, Jéssica dos Santos Gonçalves, Luciana Danielli de Araújo A transexualidade na literatura científica das ciências da saúde

serviços de saúde voltados para a discussão da transexualidade e seus desdobramentos sociais podem, paulatinamente, aumentar a produção científica do domínio transexual no Brasil e nos países da região compreendida pela LILACS.

\section{CONSIDERAÇÕES FINAIS}

Este trabalho buscou discutir a produção científica atual sobre a comunidade transexual a partir da abordagem epistemológica da análise de domínio. Buscou-se compreender a perspectiva predominante sobre transexualidade no campo das Ciências da Saúde. Para tal, foi realizada uma busca por documentos científicos na base de dados LILACS.

Tais documentos foram analisados a partir de seus dados descritivos. As contribuições desses estudos foram analisadas à luz das dimensões temáticas do domínio (dimensão biomédica; dimensão legal e da representação social dos indivíduos transexuais; dimensão do cuidado e acesso integral à saúde; dimensão do preconceito, violência, discriminação e vulnerabilidade social; e dimensão da psicanálise e da teoria da construção social). A temática das publicações que abordam o domínio foi cruzada com as dimensões de pesquisa para que pudéssemos discutir como e em que áreas do conhecimento os estudos estão sendo desenvolvidos.

Podemos perceber que a transexualidade é um domínio transversal dentro das Ciências da Saúde: a pesquisa científica sobre esse fenômeno ocorre de maneira interdisciplinar e aponta caminhos médicos, sociais, psicológicos e legais. Pela sua característica inata de não-binarismo, o tema questiona ainda as classificações e categorias, tencionando as limitações impostas pela organização do conhecimento. Isso ocorre tanto dentro das pesquisas quanto na indexação das mesmas na base de dados.

É importante ressaltar ainda que o domínio da transexualidade se desdobra em diversas instâncias, como a produção de conhecimento para o desenvolvimento de políticas, programas e ações sociais, além da produção científica. 
Os resultados desta pesquisa apontam que o campo das Ciências da Saúde na América Latina e Caribe estuda a transexualidade ainda sob uma perspectiva reduzida, uma vez que os estudos ainda são pautados por uma visão binária da questão de gênero. $O$ termo transexualidade é abordado em função da patologização dessa condição. Os desdobramentos sociais e as possibilidades de expressão não-binárias ainda não são discutidos de forma exaustiva. A teoria queer e sua perspectiva conceitual, por exemplo, ainda é muito pouco abordada na área das Ciências da Saúde.

\section{REFERÊNCIAS}

ARÁN, Márcia et al. Transexualidade e saúde pública: acúmulos consensuais de propostas para atenção integral. [Rio de Janeiro; Brasília]: UERJ; MCT; CNPq; MS, [2008?]. Texto elaborado a partir do Relatório Preliminar da Pesquisa Transexualidade e Saúde: condições de acesso e cuidado integral (IMS-UERJ/ MCT/ CNPq/ MS/ SCTIE/ DECIT); Relatório das Reuniões realizadas no Ministério da Saúde sobre O Processo transexualizador no SUS (MS, 2006; 2007); Observatório do Instituto Antígona Entendendo os fundamentos jurídicos dos direitos GLBT (2008).

BENTO, Berenice. Na escola se aprende que a diferença faz a diferença. Estudos feministas, Florianópolis, v. 19, n. 2, p. 549-559, maio/ago. 2011.

BENTO, Berenice; PELÚCIO, Larissa. Despatologização do gênero: a politização das identidades abjetas. Estudos feministas, Florianópolis, v. 20, n. 2, p. 569-581, maio/ago. 2012a.

. Vivências trans: desafios, dissidências e conformações: apresentação.

Estudos feministas, Florianópolis, v. 20, n. 2, p. 485-488, maio/ago. 2012b.

BRASIL. Constituição da República Federativa do Brasil de 1988. Disponível em:

<http://www.planalto.gov.br/ccivil 03/Constituicao/ConstituicaoCompilado.htm>. Acesso em: 30 abr. 2017.

BRASIL. Ministério da Saúde. Secretaria de Gestão Estratégica e Participativa. Departamento de apoio à gestão participativa. Política Nacional de Saúde Integral de Lésbicas, Gays, Bisexuais, Travestis e Transexuais. Brasília, DF: Ministério da Saúde, 2013. 32 p. Disponível em: $<$ http://bvsms.saude.gov.br/bvs/publicacoes/politica nacional saude lesbicas gays.pdf>. Acesso em: 20 abr. 2017. 
Débora Gomes Salles, Jéssica dos Santos Gonçalves, Luciana Danielli de Araújo A transexualidade na literatura científica das ciências da saúde

CAMPOS, Maria Luiza de Almeida; GOMES, Hagar Espanha. Princípios para modelagem de domínio: a posição de Barry Smith e de Ingetraut Dahlberg. Ci. Inf., Brasília, v. 41, n. 1, p. 81-94, jan./abr. 2014.

CAPURRO, Rafael. What is information science for? A philosophical reflection. In: INTERNATIONAL CONFERENCE FOR THE CELEBRATION OF 20th ANNIVERSARY OF THE DEPARTMENT OF INFORMATION STUDIES, UNIVERSITY OF TEMPERE, Finland, 1991. Proceedings... London; Los Angeles: Taylor Graham, 1992.

DAHLBERG, Ingetraut. Knowledge organization: a new science? Knowledge Organization, v. 33, n. 1, p. 11-19, 2006.

GUIMARÃES, José Augusto C. Análise de domínio como perspectiva metodológica em organização da informação. Ci. Inf., Brasília, v. 41, n. 1, p. 13-21, jan./abr. 2014.

HARAWAY, Donna. "Gênero" para um dicionário marxista: a política sexual de uma palavra. Cadernos Pagu, n. 22, p. 201-246, 2004. Disponível em: $<$ http://periodicos.sbu.unicamp.br/ojs/index.php/cadpagu/article/view/8644638>. Acesso em: 19 nov. 2016.

HJØRLAND, Birger. Domain analysis in information science. Eleven approaches - traditional as well as innovative. Journal of Documentation, $v$. 58, n. 4, p. 422-62, 2002.

. What is knowledge organization (KO)? Knowledge Organization, v. 35, n. 2/3, p. 86-101, 2008.

HJØRLAND, Birger; ALBRECHTSEN, Hanne. Toward a new horizon in Information Science: domain-analysis. Journal of the American Society for Information Science, v. 46, n. 6, p. 400-425, 1995.

LOURO, Guacira Lopes. Teoria queer - uma política pós-identitária para a educação. Rev. Estudos Feministas, v. 9, n. 2, p. 541-553, 2001. Disponível em: <https://periodicos.ufsc.br/index.php/ref/article/view/S0104026X2001000200012/8865>. Acesso em: 21 abr. 2017.

MATOS, Maria Izilda S. de. Estudos de gênero: percursos e possibilidades na historiografia contemporânea. Cadernos Pagu, n. 11, p. 67-75, 1998.

Disponível em:

<http://periodicos.sbu.unicamp.br/ojs/index.php/cadpagu/article/view/8634463>. Acesso em: 19 nov. 2016. 
Débora Gomes Salles, Jéssica dos Santos Gonçalves, Luciana Danielli de Araújo

A transexualidade na literatura científica das ciências da saúde

PINO, Nádia Perez. A teoria queer e os intersex: experiências invisíveis de corpos des-feitos. Cadernos Pagu, n. 28, p. 149-174, jan./jun. 2007. Disponível em:

<http://periodicos.sbu.unicamp.br/ojs/index.php/cadpagu/article/view/8644800>. Acesso em: 30 nov. 2016.

PIRES-ALVES, F. A. Cooperação internacional em Saúde na era do desenvolvimento: informação científica e tecnologias educacionais na formação de recursos humanos (1963-1983). 2011. 346 f. Tese (Doutorado em História das Ciências e da Saúde)- Fundação Oswaldo Cruz, Rio de Janeiro, 2011. Disponível em:

$<$ http://www.ppghcs.coc.fiocruz.br/images/teses/tese fernando pires.pdf $>$.

Acesso em: 30 nov. 2016.

SARACEVIC, Tefko. Ciência da informação: origem, evolução e relações.

Perspec. Ci. Inf., Belo Horizonte, v. 1, n. 1, p. 41-62, jan./jun. 1996. Disponível em: <http://portaldeperiodicos.eci.ufmg.br/index.php/pci/article/view/235/22>. Acesso em: 10 dez. 2016.

SUGA, Sueli Mitiko Yano. Desafios e perspectivas para a base de dados LILACS. In: ENCONTROS SETORIAIS FESPSP: informação em saúde, São Paulo, 27 set. 2013. São Paulo: FESPSP, 2013. Apresentação de slides.

\title{
Title
}

Transsexuality in the health sciences' scientific literature

\begin{abstract}
Introduction: The study discusses the visibility of scientific studies on transsexuality in the health field. Objetives: The study therefore questions how transsexuality is approached in the field at the present time, taking as the temporal margin the period 2014-2016. Methodology: The domain analysis, proposed by Birger Hjørland and Hanne Albrechtsen, was adopted, as a theoretical-methodological approach, for the recognition of the transgender social group as a discursive community. Data collection was performed at the LILACS database, managed by the Latin American Center for Health Sciences Information (BIREME), based on the descriptive data (focusing on the title of the articles) using the term(s) "transsexual(s)". Twenty-two documents were recovered in the period. From these, the following metadata, author, title, method and study population were used, descriptor, year of publication, being considered for the study, as central, the elements "method" and "subject" (detected from the descriptors). Results: After the corpus' analysis, it was verified that the methods adopted to approach the theme are: narrative studies, reviews with qualitative and quantitative analyzes; observational studies; theoretical reviews; content analysis; comparative studies; discourse analysis; systematic reviews, among others cited throughout this study. Conclusions: The main thematic occurrences identified from the descriptors were: people, readjustment, gender, identity, hormones and health. Within the limits of the extension and horizontality of the data, it can be deduced from the results that the Health Sciences in Latin America and the Caribbean still study transsexuality with a
\end{abstract}

Inf. Inf., Londrina, v. 22, n. 2, p. 265 - 292, maio/ago., 2017. http:www.uel.br/revistas/informacao/ 
Débora Gomes Salles, Jéssica dos Santos Gonçalves, Luciana Danielli de Araújo

A transexualidade na literatura científica das ciências da saúde

focus on the pathologization of the individuals, mainly from the representations manifested by the notions "readjustment" and "hormones ".

Keywords: Health sciences. Domain analysis. Genre. Transsexuality. Scientific production.

\section{Título}

Transexualidad en la literatura científica de las ciencias de la salud

\section{Resumen}

Introducción: El estudio discute la visibilidad de los estudios científicos sobre la transexualidad en el campo de la salud. Objetivos: El estudio cuestiona cómo la transexualidad se aborda en el campo en la actualidad, tomando como margen temporal el período 2014-2016. Metodología: El análisis de dominio, propuesto por Birger Hjørland y Hanne Albrechtsen, fue adoptado, como enfoque teóricometodológico, para el reconocimiento del grupo social transgénero como una comunidad discursiva. La recolección de datos se realizó en la base de datos LILACS, administrada por el Centro Latinoamericano de Información en Ciencias de la Salud (BIREME), a partir de los datos descriptivos (centrados en el título de los artículos) utilizando el término "transexual (s)". Veintidós documentos fueron recuperados en el período. A partir de ellos, se utilizaron los siguientes metadatos, autor, título, método y población de estudio, descriptor, año de publicación, considerados como centrales, los elementos "método" y "sujeto" (detectados a partir de los descriptores). Resultados: El análisis del corpus, se verificó que los métodos adoptados para abordar el tema son: estudios narrativos, revisiones con análisis cualitativos y cuantitativos, estudios observacionales, revisiones teóricas, análisis de contenido, estudios comparativos, análisis de discurso, revisiones sistemáticas. Conclusiones: En el marco de los límites de extensión y horizontalidad de los datos, se puede deducir de los resultados que las Ciencias de la Salud en América Latina América y el Caribe siguen estudiando la transexualidad con un enfoque en la patologización de los individuos, principalmente a partir de las representaciones manifestadas por la nociones "reajuste" y "hormonas".

Palabras clave: Ciencias de la salud. Análisis de dominio. Género. Transexualidad. Producción científica.

Recebido: 10.03 .2017

Aceito: 25.08 .2017

Inf. Inf., Londrina, v. 22, n. 2, p. 265 - 292, maio/ago., 2017.

http:www.uel.br/revistas/informacao/ 